\title{
Pre-service teachers' conceptions and competences on digital literacy in an EFL academic writing setting
}

\author{
Salim Nabhan \\ English Language Education Department, Faculty of Social Sciences and Humanities, \\ Universitas PGRI Adi Buana Surabaya, Indonesia Jl. Dukuh Menanggal XII, Surabaya, Jawa Timur 60234
}

\begin{abstract}
This case study seeks to examine pre-service teachers' digital literacy conceptions in an EFL academic writing context and aims to identify pre-service teachers' competences concerning the predominant dimensions of digital literacy encompassing critical thinking, online safety skills, digital culture, collaboration and creativity, finding information, communication, and functional skills. This case study involved both quantitative and qualitative data taken from 107 preservice teachers' online questionnaires and one 5-member focus group discussion delivered to pre-service teachers taking academic writing subjects in English Language Education Department in an urban university in Indonesia. In general, the result of the study revealed that the pre-service teachers' conceptions of digital literacy were principally associated with the narrow proficiency of utilizing online tools and technological devices and set aside a critical mindset. Further, in spite of the fact that most participating students were found to have lack of understanding of critical thinking and digital culture towards digital literacy, they appeared to possess the competencies of finding information, communication, and functional skills. Additionally, quantitative result of the pre-service teachers' competences demonstrated that communication dimension was the highest of all with the mean value of 3.95 , followed by online safety skills (3.87), finding information (3.79), critical thinking (3.77), functional skills (3.75), as well as collaboration and creativity (3.43). The lowest mean (3.40) belonged to digital culture dimension. The findings have important implications for developing digital literacy framework in an EFL academic writing.
\end{abstract}

Keywords: Digital literacy; digital competences; EFL academic writing

\begin{tabular}{|c|c|c|}
\hline $\begin{array}{l}\text { First Received: } \\
9 \text { October } 2020 \\
\text { Final Proof Received: } \\
27 \text { May } 2021 \\
\end{array}$ & $\begin{array}{c}\text { Revised: } \\
22 \text { January } 2020\end{array}$ & $\begin{array}{l}\text { Accepted: } \\
\text { 12 March } 2020 \\
\text { Published: } \\
\text { 31 May 2021 } \\
\end{array}$ \\
\hline \multicolumn{3}{|c|}{$\begin{array}{l}\text { How to cite (in APA style): } \\
\text { Nabhan, S. (2021). Pre-service teachers' conceptions and competences on digital literacy in an } \\
\text { EFL academic writing setting. Indonesian Journal of Applied Linguistics, 11(1), 187-199. } \\
\text { https://doi.org/10.17509/ijal.v11i1.34628 }\end{array}$} \\
\hline
\end{tabular}

\section{INTRODUCTION}

It is commonly believed that today's learners are considered to be digital natives, naturally possessing the ability to use digital technologies (Prensky, 2001). However, several studies indicated that critical number of students nowadays certainly do not master the expected skills of the literacy -only at the basic level-, and they need further training to use digital tools for effective learning purposes (Bennett et al., 2008; Cote \& Milliner, 2017; OzdamarKeskin et al., 2015; Shariman et al., 2012).
Therefore, overgeneralizing the competencies of students as digital natives would be perilous.

Since the nature of digital literacy has expanded due to the technological development, a number of digital literacies frameworks have proposed a set of skills or competences such as critical thinking, communication, online safety, collaboration, creativity, and cultural skills (Belshaw, 2015; Calvani et al., 2008; Carretero et al., 2017; Ferrari, 2013; Hague \& Payton, 2010; Jisc, 2015; Son, 2015). Concurrently, while students' technology- 
related perceptions in general have been examined based on the literature-based conception of digital literacy (List, 2019; List et al., 2020; Rambousek et al., 2016), pre-service teachers' beliefs related to their digital literacy in association with their EFL academic writing setting are still under explored. These pre-service teachers' beliefs may impact to their attitude and the instructional choices towards digital learning and teaching environment.

Skills or competencies of digital literacy based on the proposed frameworks have been identified generally in several studies (García-Martín \& García-Sánchez, 2017; Phuapan et al., 2016; Ozdamar-Keskin et al., 2015; Shariman et al., 2012). However, to date, little attention has been done on the examination of digital literacy specifically in the context of EFL academic writing. Therefore, the present study seeks to answer these two following research questions:

1. How do pre-service English teachers perceive digital literacy in EFL academic writing context?

2. What are pre-service English teachers' competences of digital literacy within an EFL academic writing setting?

\section{Digital literacy and its conceptions}

Many researchers and practitioners have given various definitions of digital literacy, and there is no one set of concurred meaning of digital literacy. A general definition of digital literacy was suggested by Martin (2006):

Digital literacy is the awareness, attitude and ability of individuals to appropriately use digital tools and facilities to identify, access, manage, integrate, evaluate, analyze and synthesize digital resources, construct new knowledge, create media expressions, and communicate with others, in the context of specific life situations, in order to enable constructive social action; and to reflect upon this process. (p.19)

A variety of models and frameworks have proposed the various dimensions of digital literacies, skills, or competencies. Calvani et al. (2008) proposed dimensions of digital literacy including technological dimension, cognitive dimension, ethical dimension, and integration between the three dimensions. Technological dimension refers to exploration of modern innovative setting in adaptable way. Cognitive dimension requires critical thinking toward information. Ethical dimension relates the responsibility in the digitally social interaction. Finally, the integration between the three dimensions encompasses the collaboration of new knowledge development.

Hague \& Payton (2010) associated digital literacy with the components of functional skills, creativity, critical thinking and evaluation, cultural and social understanding, collaboration, the ability to find and select information, effective communication, and e-safety. Next, the digital competence framework was also suggested by Ferrari (2013) into the areas of digital competence involving information, communication, contentcreation, safety, and problem-solving. Besides those five areas, he also created three proficiency levels covering A (foundation level), B (intermediate level), and C (advanced level). The levels represent a general overview of the area content through descriptors for three proficiency levels as in the CEFR for Languages.

Jisc (2015) defined and updated digital literacy in an academic context as the proficiency which is relevant for living, learning, and working in a digital society and considered six elements to develop students' digital literacy: (a) ICT proficiency, (b) information, data and media literacy, (c) digital creation, problem solving and innovation, (d) digital communication, collaboration and participation, (e) digital learning and development, and (f) digital identity and wellbeing. Additionally, Belshaw (2015) introduced elements of digital literacy incorporating cultural, cognitive, constructive, communicative, confident, creative, critical, and civic elements.

Work by Son (2015) presented elements of digital literacy including information search and evaluation, creation, communication, collaboration, and online safety. He has designed digital literacy questionnaire for language learners and language teachers. Finally, Carretero et al. (2017) introduced the latest issue of DigComp 2.1 updating the previous version, 2.0 into the competence area of information and data literacy, communication and collaboration, digital content creation, safety, and problem solving. They have developed the framework in five dimensions: (a) competence area, (b) competence descriptors and titles, (c) proficiency levels for each competence into foundation (levels 1 and 2), intermediate (levels 3 and 4), advanced (levels 5 and 6), and highly specialized (levels 7 and 8), (d) knowledge, skills, and attitudes, and (e) example of use. Proficiency level is differentiated based on the complexity of tasks, autonomy, and cognitive domain.

Above conceptions and frameworks of digital literacy have confirmed the complexity of defining digital literacies and related dimensions. Despite several competences were established in the framework, identifying the indicators in each competence is challenging due to the lack of clear distinction and overlap between the concepts. Considering the prospects application of the framework for competence evaluation of digital literacy, a more integrated and common framework is needed.

Digital literacy in EFL academic writing context Due to the advancement of technology, the nature of writing has undergone dramatic changes in today's digital age. Writing practices have expanded from 
the traditional notions of literacies into digital literacies towards integration of printed based-text with multimodal texts (Nabhan \& Hidayat, 2018). Moreover, the development of technology has crucially altered the forms, genre, and purpose of writing (Chun et al., 2016; Zheng \& Warschauer, 2017). Therefore, writing pedagogy should embrace the development of new digital genres (Elola \& Oskoz, 2017). They argued that such technologymediated tools could enhance students' writing practices. Hence, the pedagogical implication caused by the emergence of technology has shifted into incorporation of multimodal and digital literacies.

There have been many approaches of teaching writing such as product and process writing approach. While, product approach refers to traditional approach that focuses on the production of a piece of paper, the process approach emphasizes on the process itself by involving varied classroom activities (Nabhan, 2019). The issues of multimodality and digital literacy as the elements of new approach of literacy pedagogy and so called "multiliteracies" become dominant (Jewitt, 2005; NLG, 1996). The multiliteracies is a pedagogical approach involving six different modes of meaning making: linguistic, visual, audio, gestural, spasial, and multimodal (NLG, 1996). A study conducted by Nabhan (2019) proposed framework of multiliteracies that is incorporated in the writing process approach to facilitate the students in EFL writing classroom. The framework was designed to expand the teaching English writing by integrating the stages of process writing approach including pre writing, planning and organizing, drafting, reflection, peer/tutor review, revision, editing and proofreading, and publishing, as well as multilitercies pedagogy involving multimodality or multiple modes of meaning making such as images, audio, and video as well as digitality.

Several studies have indicated that writing activities such as reviewing, giving feedback, discussion, revision, and collaborative writing were conducted digitally using online tools such as Google Docs and other applications (Abrams, 2019; Ene \& Upton, 2018; Saeed \& Ghazali, 2017). The findings suggest that technology facilitated the
English writing classroom through synchronous and asynchronous electronic review and feedback, and it allowed the learners to work collaboratively in their writing classroom activities through computersupported collaborative writing tools. However, some factors or challenges also contributed to the successful learning activities such as students' qualification, learning facilities, motivation, and time (Nabhan, 2019; Son et al., 2017). The study suggested that practical guidelines and opportunities to learn digital tools and resources are very needed in language learning. Learners necessitate to improve their digital literacy skills in order that they become independent learners who can utilize the technology for their language learning in authentic contexts.

\section{METHODS \\ Study design}

This research involved both qualitative and quantitative case study approach to give a depth account of pre-service teachers' conception and competencies of digital literacy in EFL academic writing context. Addressing the research problem, several research methods were utilized: open-ended and close-ended questionnaires and focus group discussion. While the methodological triangulation of open-ended questionnaire, interviews, and focus group discussions were used to identify the perceptions of pre-service teachers towards digital literacy in an EFL academic writing setting, the closed-ended questionnaires were administered to examine pre-service teachers' digital competences contextualized in EFL academic writing.

\section{Study participant}

Participants were 107 pre-service teachers, 22 males $(20.54 \%)$ and 85 females $(79.44 \%)$ of the second, third, and fourth year majoring English Language Education, Faculty of Teacher Training and Education, Universitas PGRI Adi Buana Surabaya, East Java, Indonesia. The participants have joined the class of English academic writing and wrote academic articles. Their demographic details are presented in Table 1.

Table 1

Demographic Details of the Participants $(\mathrm{N}=107)$

\begin{tabular}{llcc}
\hline Properties & Details & Number & Percentage \% \\
\hline Gender & Male & 22 & $20.56 \%$ \\
& Female & 85 & $79.44 \%$ \\
Age Group & $19-20$ & 42 & $39.25 \%$ \\
& $21-22$ & 46 & $42.99 \%$ \\
& $23-24$ & 15 & $14.02 \%$ \\
& $25-$ above & 4 & $3.74 \%$ \\
Year & Second year (Semester 4) & 51 & $47.66 \%$ \\
& Third year (Semester 6) & 11 & $10.06 \%$ \\
& Fourth year and above (Semester 8) & 45 & $42.06 \%$ \\
\hline
\end{tabular}

Copyright (C) 2021, authors, e-ISSN: 2502-6747, p-ISSN: 2301-9468 


\section{Data collection}

There were two types of data collections, qualitative and quantitative. The qualitative data were taken from the 107 pre-service teachers' open-ended questionnaires and one 5-member focus group discussion. Focus group discussion involved five pre-service teachers that were chosen randomly. The focus group questions were as follows:

- From your own opinion, how do you define digital literacy?

- In your own perspectives, what skills related to digital literacy you think to be necessary to learn English academic writing? Explain them!

- Do you think that digital literacy is important? Give the reason why?

- $\quad$ There are some factors affecting digital literacy. Please identify which ones representing yourselves.

- What are the challenges in digital literacy?

The quantitative data were derived from closedended questionnaires that were distributed to 107 pre-service teachers. The questionnaires were designed by considering the relevant skills or competences among the proposed digital literacy framework contextualized in EFL academic writing settings. The framework offers a more nuanced view of "Digital Academic Writing Skills" contrasting areas of competences. There are seven competences which are pertinent embracing critical thinking, online safety skills, digital culture, collaboration and creativity, finding information, communication, and functional skills. Questionnaires followed Likert Scale with five levels of agreement: 'strongly disagree' $=1, \quad$ 'disagree' $=2$, 'neither agree or disagree' $=3$, 'agree' $=4$, and strongly agree' $=5$ (Brown, 2010). To verify the validity of the questionnaire, two experienced EFL lecturers were invited to give feedback of the items. Besides, the reliability of the questionnaires was measured using Cronbach's Alpha. The result showed that while, the overall score was 0.938 indicating that the questionnaire was reliable, the reliability coefficient of the critical thinking was 0.758 , the reliability coefficient of online safety skills was 0,756 , the reliability coefficient of digital culture was 0.761 , the reliability coefficient of collaboration and creativity was 0.621 , the reliability coefficient of finding information was 0.702 , the reliability coefficient of communication was 0.844 , and the reliability coefficient of functional skills was 0.836 . From the result, it indicates that the questionnaires of each dimension were also reliable.

\section{Ethical consideration}

Explanation was given to the participants regarding the purposes of the study and some other relevant information prior to participating the study. The written consent was also administered to give explanation to the participants and show agreement to voluntarily get involved in the research (Mackey \& Gass, 2005). In addition, the data from the participants were recorded and stored in a safe place.

\section{Data analysis}

The qualitative data derived from the pre-service teachers' open-ended questionnaire and focus group discussions were developed into codes and categories. Then, the themes were generated based on the research problem. There were four themes emerged in the study including basic conception of digital literacy, competences related to digital literacy, awarness of the importance of digital literacy, and challenges of digital literacy. Data triangulation and member checking were also employed to validate the research finding (Mackey $\&$ Gass, 2005). With reference to quantitative data from the open-ended questionnaire, descriptive analysis was used. The researcher used statistical analysis software package SPSS 16.

\section{FINDINGS}

How do pre-service English teachers perceive digital literacy in EFL academic writing context? Based on the result of open-ended questions and focus group discussion, qualitative analyses revealed four themes regarding pre-services teachers' belief about digital literacies contextualized in EFL academic writing: 1) basic conception of digital literacy, 2) competences related to digital literacy, 3) awarness of the importance of digital literacy, and 4) challenges of digital literacy.

\section{Basic conception of digital literacy}

A number of participants reported the narrow conception of digital literacy into skill-based competencies. Digital literacy involved a set of skills necessary for academic writing such as using software, finding information, and communication. Related to using software, this was reflected from the student's response such as: "Digital literacy in my opinion is when we can use all of platforms like Canvas and Google Classroom very well" (S.18).

Another response focusing on finding information or academic references was explained by a student: "It's helpful for us nowadays to gather some necessary information related to academic and the other things for our need." (S. 5). In addition, a digital literate student was conceptualized as person who can use digital media to communicate or to have social networking. A student stated, "An individual who can utilize digital media for accessing or operating to make a relationship with others." (S. 24). In this case, academic social 
networking through online media is considered in academic writing.

From above statements, some participants indicated that what they perceived concerning digital literacy was still in the basic level. In other words, the conception of digital literacy was not comprehensively understood in the sense that digital literacy integrates all the aspects of creativity, esafety, and critical thinking in evaluating, analyzing the information, and other substantial aspects of digital literacy, not only how to operate the digital platforms.

\section{Competences related to digital literacy}

Related to digital literacy competences that are necessary for English academic writing, some students explained several competences. Statements corresponding with critical thinking were explained by a student:

The suitable skill that is connected to digital literacy is critical thinking skills. It is very important to interpret much information from the internet. We as the students need to do some research to find acceptable references especially to acquire academic writing skills in English. We also cultivate the information and paraphrase them and try to avoid such as plagiarism. (S. 12).

Another student, focusing on tech savvy as one of digital literacy competences, explained, "Safety in knowing copyright and plagiarism in academic writing, for me, is the most important thing in digital literacy because by knowing this, we will be safe in doing academic writing." (S. 32). Concerning technical skills in using digital devices or applications, a student said, "Skills in utilizing digital media such as using online dictionaries, plagiarism checkers, Mendeley application, and others." (S. 55). A student also further stated that creativity is also one of the skills needed in academic writing. This is evidenced through his statement "Creativity, being able to weigh up opportunities in an entrepreneurial manner and ask the right questions to generate new ideas." (S. 23). Finally, searching information is also considered necessary in academic writing which is represented in one of the students' explanation such as: "filtering and selecting content. It is the ability to search, filter and select information appropriately according to the desired needs." (S. 76).

Although several participants showed lack of understanding toward the conception of digital literacy, several participants suggested range of skills needed in digital literacy for academic writing such as critical thinking, tech savvy, technical skills, creativity, and searching information.

\section{Awareness of the importance of digital literacy}

With respect to the importance of digital literacy, most students expressed their awareness that digital literacy is crucial for their academic writing since it helps them develop their ideas, improve their writing skills, provide them to write effectively and efficiently. Besides, digital literacy supports todays' nature of reading and writing that are mostly done digitally.

Focusing on developing the ideas in academic writing, one student stated, "Yes, because we can access many sources such as journals, online books, the web or others to help us to develop our ideas in the process of academic writing." (S. 65). "Yes, I think, digital literacy is important for academic writing since students could gain knowledge to improve their writing skill and relate sources for their writing," one student also said (S. 83) related to the improvement of writing skills. Another reason why digital literacy is necessary was expressed by a student such as: "Yes, because if we are digitally literate, we can access all information easily and quickly (S. 48). This is to say that they can utilize digital media to help their process of academic writing. Finally, another student's response demonstrated nowadays nature of reading and writing such as: "yes, because, nowadays a lot of books, journal, and other sources are uploaded in online platform, so we also need to have digital literacy." (S. 75).

\section{Challenges of digital literacy}

It is also found several students who identified some limitations in their digital literacy. Lack of digital literacy covered several aspects such as technical issues, critical thinking, and the understanding of plagiarism issues. Moreover, traditional mindset and limited resources contributed to the students' development of digital literacy.

Technical issues were reflected in responses such as: "Using devices and software as well as creating and editing. Not all people can use them." (S.30). Concerning lack of critical thinking, a student stated, "Filtering content is pretty challenging for me. I need to learn analyzing the information more detail to get trustworthy facts," (S. 18). It was supported as well by the student' response such as:" The most challenging skill in digital literacy is how we can choose the reliable sources through digital media for our academic writing. (S. 86). In addition, related to the understanding of the plagiarism issue as one of the challenges, the student explained:

I think the most challenging skill in digital literacy is how to share or communicate the information that we have already gotten to the media. We must concern about the plagiarism, so we have to be more critical in citation and everything to prevent the plagiarism, it is quite hard because when you do not know how to cite the information from the Internet, you will be seen as someone who does plagiarism. (S. 58).

At the same time, several students also described about the changing of mindset from 
traditional thinking into digital thinking. A student expressed, "When we are the type of a person who loves comfort zone, we think it is more convenient to do anything that is considered traditional in this era." (S.2). Finally, some students considered limited resources lead to the development of digital literacy. "Every person has their own problems in learning literacy. For example, people who are in low economic would get limited digital access. Digital device is the facility for people who are in the modern city and high economic status," (S. 33) a student said.

Overall, the findings suggest that although preservice teachers' conceptions of digital literacy in academic writing context were merely associated with the ability of using technology, they were aware of the importance of digital literacy with several challenges they faced.

R.Q. 2: What are pre-service teachers' competences of digital literacy within an EFL academic writing setting?

It is apparent from table 2 that overall quantitative result of digital literacy competencies in an EFL academic writing context showed that communication dimension was the highest of all with the mean value of 3.95 , followed by online safety skills (3.87), finding information (3.79), critical thinking (3.77), functional skills (3.75), as well as collaboration and creativity (3.43). The lowest mean (3.40) belonged to digital culture dimension.

\section{Critical thinking}

The dimension of critical thinking in which participants were requested to rate themselves in analyzing and evaluating information from the Internet for their academic writing showed that the use of reliable sources (Q1) was rated in the highest score with the numerical value of 4.01 . While the understanding of online references (Q2) and finding the ideas online (Q4) showed the mean score of 3.84 and 3.81 respectively, the information or data evaluation (Q3) and primary sources identification (Q6) performed 3.79 and 3.65 respectively. The lowest mean score was the ability to establish materials connectivity from different online sources (Q5) with the numerical score of 3.54. The data can be seen in the following Table 3 .

Table 2

Means and Standard Deviation of Digital Literacy Competences

\begin{tabular}{lccc}
\hline Dimensions of Digital Literacy & N & Mean & SD \\
\hline Critical Thinking & 107 & 3.77 & 0.49 \\
Online Safety Skills & 107 & 3.87 & 0.58 \\
Digital Culture & 107 & 3.40 & 0.62 \\
Collaboration and Creativity & 107 & 3.43 & 0.60 \\
Finding Information & 107 & 3.79 & 0.51 \\
Communication & 107 & 3.95 & 0.56 \\
Functional Skills & 107 & 3.75 & 0.51 \\
\hline
\end{tabular}

Table 3

Mean and Standard Deviation of Critical Thinking

\begin{tabular}{|c|c|c|c|c|}
\hline \multicolumn{2}{|c|}{ Dimension and Questionnaire Items } & $\mathbf{N}$ & Mean & SD \\
\hline \multicolumn{5}{|c|}{ Critical Thinking } \\
\hline Q1 & I use reliable sources for my academic writing & 107 & 4.01 & 0.64 \\
\hline Q2 & $\begin{array}{l}\text { I can understand which information in the Internet that I can or } \\
\text { cannot use as references for my writing }\end{array}$ & 107 & 3.84 & 0.80 \\
\hline Q3 & $\begin{array}{l}\text { I analyze and evaluate online information or data for academic } \\
\text { works }\end{array}$ & 107 & 3.79 & 0.82 \\
\hline Q4 & I can find and develop the ideas related to certain topics & 107 & 3.81 & 0.66 \\
\hline Q5 & $\begin{array}{l}\text { I can establish connection regarding materials or issues from } \\
\text { different online sources }\end{array}$ & 107 & 3.54 & 0.76 \\
\hline Q6 & I can identify the primary sources and the author(s) of the articles & 107 & 3.65 & 0.72 \\
\hline
\end{tabular}

\section{Online safety skills}

Online safety skills were examined to identify the participants' awareness regarding their personal security when using internet such as the issue of copyright, digital footprint, and plagiarism. Based on the data in Table 4, the result indicated that understanding plagiarism (Q9) takes the highest position with the mean score of 4.15 , followed by putting the credits (authors) from the online references (Q10) with the mean score of 4.06 . Additionally, the mean score of 3.79 and 4.06 respectively belong to the awareness of copyright of online materials (Q7) and online plagiarism checking (Q11). Finally, the lowest rank (3.65) appeared in the participants' understanding of the security issues when online $(\mathrm{Q} 8)$.

\section{Digital culture}

Digital culture as one of digital literacy dimensions was examined to identify the participants' involvement in online academic communities as part of academic culture. As seen in Table 5, the result 
showed that browsing some organization/forum/ association websites (Q15) was in the highest position with the numerical value of 3.63 , followed by YouTube channel subscription (Q 14) and joining messaging services of certain online forum (Q 13) with mean score of 3.58 and 3.40 respectively. While the online learning forum/communities in social media participation (Q12) performed the mean score of 3.31, and joining academic social network/professional networking website/apps (Q16) reached the mean score of 3.31. Finally, joining webinar related to academic writing (Q17) was in the lowest mean score of 3.16 .

\section{Collaboration and creativity}

The dimension of collaboration and creativity in digital literacy toward academic writing in terms of working together with friends using online collaboration tools (Q18) performed the highest mean score of 3.64. While sharing some references and giving feedback (Q 19) as well as creating digital images (Q 20) showed the mean score of 3.48 and 3.31 respectively. Additionally, the lowest mean score of 3.28 (Q 21) belonged to the use of video editor and digital videos (Q 21). See the data in the following Table 6.

\section{Finding Information}

Finding information as one dimension of digital literacy in academic writing was questioned to explore the participants' digital competences. As shown in Table 7, the participants rated the use of online dictionaries for academic writing (Q 23) as the highest score with the mean score of 4.23. The second highest was the use of Google for searching references $(\mathrm{Q} 22)$ with the mean score of 4.03. The next rank belonged to the ability to search reputable online journals (Q 25) and the use of websites or links for free e-book (Q 24) with the mean score of 3.69 and 3.64 respectively. The lowest mean appeared in the use of online application to retrieve and analyze academic citation (Q 26) with the mean score of 3.33 .

Table 4

Mean and Standard Deviation of Online Safety Skills

\begin{tabular}{|c|c|c|c|c|}
\hline \multicolumn{2}{|c|}{ Dimension and Questionnaire Items } & $\mathbf{N}$ & Mean & SD \\
\hline \multicolumn{5}{|c|}{ Online Safety Skills } \\
\hline Q7 & I am aware of copyright or ownership of any online materials & 107 & 3.79 & 0.82 \\
\hline Q8 & I can understand the security issues when online & 107 & 3.65 & 0.78 \\
\hline Q9 & I understand what plagiarism is & 107 & 4.15 & 0.70 \\
\hline Q10 & $\begin{array}{l}\text { I put credits (authors) when citing online references such as } \\
\text { online journals, books or others }\end{array}$ & 107 & 4.06 & 0.80 \\
\hline Q11 & $\begin{array}{l}\text { I check my article using online plagiarism checker before } \\
\text { submission/publication }\end{array}$ & 107 & 3.71 & 0.95 \\
\hline
\end{tabular}

Table 5

Mean and Standard Deviation of Digital Culture

\begin{tabular}{|c|c|c|c|c|}
\hline \multicolumn{2}{|c|}{ Dimension and Questionnaire Items } & $\mathbf{N}$ & Mean & SD \\
\hline \multicolumn{5}{|c|}{ Digital Culture } \\
\hline Q12 & $\begin{array}{l}\text { I follow online learning forum/communities in social media such as } \\
\text { Facebook or Instagram on the topic of academic writing }\end{array}$ & 107 & 3.31 & 0.98 \\
\hline Q13 & $\begin{array}{l}\text { I join messaging services of certain learning forum/community } \\
\text { such as WA or Telegram Group }\end{array}$ & 107 & 3.40 & 0.98 \\
\hline Q14 & I subscribe YouTube Channel of academic content videos & 107 & 3.58 & 0.95 \\
\hline Q15 & $\begin{array}{l}\text { I browse some organization/forum/association websites related to } \\
\text { academic materials }\end{array}$ & 107 & 3.63 & 0.73 \\
\hline Q16 & $\begin{array}{l}\text { I have academic social network/professional networking } \\
\text { website/apps such as Research Gate or Academia for sharing } \\
\text { knowledge }\end{array}$ & 107 & 3.30 & 0.91 \\
\hline Q17 & I join digital webinar on the topic of academic writing & 107 & 3.16 & 0.89 \\
\hline
\end{tabular}

Table 6

Mean and Standard Deviation of Collaboration and Creativity

\begin{tabular}{|c|c|c|c|c|}
\hline \multicolumn{2}{|c|}{ Dimension and Questionnaire Items } & $\mathbf{N}$ & Mean & SD \\
\hline \multicolumn{5}{|c|}{ Collaboration and Creativity } \\
\hline Q18 & $\begin{array}{l}\text { I work together with my friends in doing writing assignment using } \\
\text { online collaboration tools such as WA Group, Google Docs or } \\
\text { other tools }\end{array}$ & 107 & 3.64 & 0.89 \\
\hline Q19 & $\begin{array}{l}\text { I share some references and give feedbacks to my friends related to } \\
\text { certain topics }\end{array}$ & 107 & 3.48 & 0.81 \\
\hline Q20 & $\begin{array}{l}\text { I can create from word processing to digital images for academic } \\
\text { works }\end{array}$ & 107 & 3.31 & 0.73 \\
\hline Q21 & $\begin{array}{l}\text { I can operate video editor and create digital videos related to my } \\
\text { writing assignment }\end{array}$ & 107 & 3.28 & 1.04 \\
\hline
\end{tabular}


Table 7

Mean and Standard Deviation of Finding Information

\begin{tabular}{|c|c|c|c|}
\hline Dimension and Questionnaire Items & $\mathbf{N}$ & Mean & SD \\
\hline \multicolumn{4}{|l|}{ Finding Information } \\
\hline $\begin{array}{l}\text { Q22 I can use Google with appropriate key words to find some } \\
\text { references needed }\end{array}$ & 107 & 4.03 & 0.69 \\
\hline $\begin{array}{l}\text { Q23 I use online dictionaries to check my vocabulary used in academic } \\
\text { works }\end{array}$ & 107 & 4.23 & 0.76 \\
\hline Q24 I know some websites or links of free e-book such as pdfdrive.com & 107 & 3.64 & 0.79 \\
\hline $\begin{array}{l}\text { Q25 I am able to search some reputable open-access journals from } \\
\text { Internet }\end{array}$ & 107 & 3.69 & 0.72 \\
\hline $\begin{array}{l}\text { Q26 I can use online application that retrieves and analyzes academic } \\
\text { citation such as Publish or Perish }\end{array}$ & 107 & 3.33 & 0.82 \\
\hline
\end{tabular}

\section{Communication}

The participants reported the highest mean score of 4.39 regarding the use of social networking sites ( $Q$ 27 ) in their communication competences followed by instant messaging services (Q 28) and email platform (Q 32) with the mean score of 4.36 and 4.32 respectively. While the use audio/video conferencing services (Q 29) was reported to get the mean score of 4.27 , the use of video sharing or live streaming (Q 30) was noted to get the mean score of 4.19. The next rank belonged to the use of google forms (Q 33) with the mean score of 3.59, the use blogs/vlogs/personal websites (Q 31) with the mean score of 3.56, and understanding of how to correspond (Q 35) with the mean score of 3.50. Moreover, the lowest mean score of 3.33 was the use of google scholar for need of academic writing (Q 34). The data can be seen in Table 8 .

Table 8

Mean and Standard Deviation of Communication

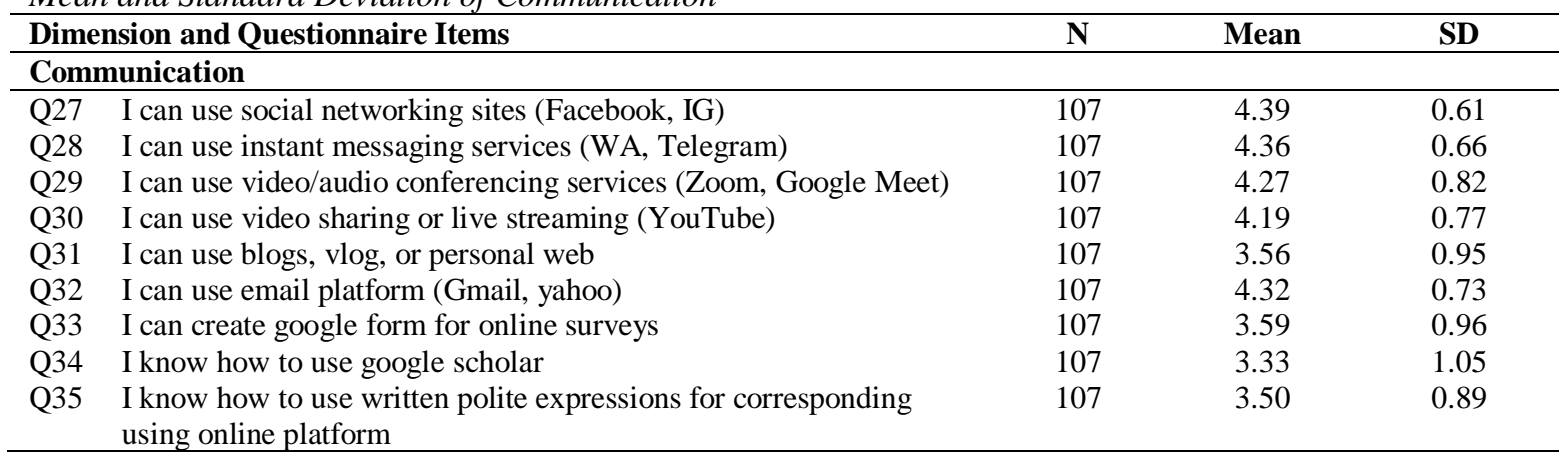

\section{Functional Skills}

Finally, the dimension of functional skills in digital literacy for academic writing in terms of the use of presentation application (Q 38) was rated in the highest mean score of 4.31. Not far from first rank, the use of word processing application (Q 36) was in the second highest score of 4.26 , followed by the use of online learning management system ( $Q$ 39) with the mean score of 4.20. Moreover, the participants rated the use of reference management software as the third lowest mean score of 3.32, followed by the use of paraphrasing-summarizing online tools ( $\mathrm{Q} 44)$ in the second lowest mean score of 3.28. The last, the use of reference management software (Q 47) was noted to be the lowest of all with the mean score of 2.74. The complete data were shown in Table 9.

\section{DISCUSSION}

This study has two goals: first, new perspectives of the conception of digital literacy in an EFL academic setting which are derived from pre-service teachers, and second, identification of pre-service teachers' competences concerning the predominant dimensions of digital literacy comprising critical thinking, online safety skills, digital culture, collaboration and creativity, finding information, communication, and functional skills which are related to academic writing context.

\section{The conceptions of digital literacy in EFL academic writing}

Conception of digital literacy in academic writing setting was perceived by a number of participants as exclusively limited to a set of skills such as the ability to operate device or application, searching for information online, and communication. These pre-service teachers might use technology without involving the aspect of creativity, e-safety, and critical thinking in evaluating, analyzing the information, and other substantial aspects of digital literacy. In other words, what they perceived regarding digital literacy was still in surface level. The conception of digital literacy needs to be comprehensively understood as being suggested by Hague and Payton (2010), Ferrari (2013), Belshaw (2015), Son (2015), and Carretero et al. (2017) in 
which digital literacy involves several elements such as functional skills, e-safety, effective communication, ability to find and select information, collaboration, cultural and social understanding, critical thinking and evaluation, as well as creativity. Lack of understanding regarding the conception of digital literacy might limit preservice teachers' digital literacy development. The finding related to the basic conception of digital literacy is also in line with the study by Ata \&
Yildirim (2019) showing that despite pre-service teachers had high positive perceptions of digital literacy, they still encountered insufficient understanding of cognitive skills. Therefore, the projection of digital literacy education to pre-service teachers included in the curricula is necessary as they will be teacher in the future, and the use of technology is inevitable.

Table 9

Mean and Standard Deviation of Functional Skills

\begin{tabular}{|c|c|c|c|c|}
\hline \multicolumn{2}{|c|}{ Dimension and Questionnaire Items } & $\mathbf{N}$ & Mean & SD \\
\hline \multicolumn{5}{|c|}{ Functional Skills } \\
\hline Q36 & I can use word processing application (e.g. Ms. Words) & 107 & 4.26 & 0.69 \\
\hline Q37 & I can use spread sheet application (e.g. Ms. Excel) & 107 & 3.72 & 0.90 \\
\hline Q38 & I can use presentation application (e.g. Ms. Power Point) & 107 & 4.31 & 0.65 \\
\hline Q39 & $\begin{array}{l}\text { I can use online learning management system (Google } \\
\text { Classrooms, Canvas, etc.) }\end{array}$ & 107 & 4.20 & 0.72 \\
\hline Q40 & I can use Google docs for sharing & 107 & 3.90 & 0.75 \\
\hline Q41 & $\begin{array}{l}\text { I can edit and publish my work digitally using platforms like } \\
\text { PDF or video }\end{array}$ & 107 & 3.88 & 0.80 \\
\hline Q42 & I use online free/paid grammar checker & 107 & 3.88 & 0.85 \\
\hline Q43 & I use free/paid plagiarism checker & 107 & 3.77 & 0.89 \\
\hline Q44 & I use some free website for paraphrasing and summarizing & 107 & 3.28 & 1.01 \\
\hline Q45 & $\begin{array}{l}\text { I can use data analysis software for research such as SPSS, } \\
\text { Nvivo, etc }\end{array}$ & 107 & 2.74 & 0.91 \\
\hline Q46 & $\begin{array}{l}\text { I can use reference management software such as Mendeley or } \\
\text { Zotero }\end{array}$ & 107 & 3.32 & 0.94 \\
\hline
\end{tabular}

Several participants suggested range of skills needed in digital literacy for academic writing such as critical thinking, tech savvy, technical skills, creativity, and searching information, although they lacked understanding toward the conception of digital literacy. In general, this result echoes the variety models of framework that the pre-service teachers need to learn to be digitally literate (Belshaw, 2015; Calvani et al., 2008; Carretero et al., 2017; Ferrari, 2013; Hague \& Payton, 2010; Jisc, 2015; Son, 2015). Finding information skills seemed to be predominant among pre-service teachers' responses. This can be understood since the use of search engine has become the integral part of pre-service teachers' learning activities especially in finding academic references (Kurniasih et al., 2018). However, some other skills such as ethical dimension (Calvani et al., 2008) and collaboration (Carretero et al., 2017; Hague \& Payton, 2010; Jisc, 2015; Son, 2015) seemed to be missing from preservice teachers' perspective. Digital literacy is related to collaboration competence. Studies suggested that web based-collaborative learning is principal to develop students' digital literacy (Fu \& Pow, 2011; Pow \& Fu, 2012).

Most pre-service teachers responded their awareness of the importance of digital literacy in academic writing. Initial stages in process writing including pre-writing to generate and develop ideas as well as planning and organizing are critical for pre-service teachers, pre-service teachers tended to search academic references in the Internet. This is the space where digital literacy is needed, including how they evaluate and analyze the information. Nabhan (2019) suggested multiliteracies and process writing approach framework with multimodal and digital integration. In addition, several digital tools provide some facilities to help students improve their writing. As the result they can write more effectively and efficiently. This result corresponds with the by Chun et al., (2016); Abrams (2019) and Zheng \& Warschauer (2017) that explored the potential of technologies for facilitating writing process. More specific, pre-service teachers also noted that being digitally literate today is inevitable since the nature of nature of reading and writing has expanded toward digitalization as being identified by Nabhan and Hidayat (2018).

Several challenges for digital literacy in academic writing setting were also encountered such as technical issues, critical thinking, and the understanding of plagiarism issues. Regarding technical issues, this finding support the previous research by Lam \& Wong (2015) suggesting that insufficient IT skills became one of the major challenges in digital literacy. Moreover, critical thinking has been the issue in digital literacy since most participants reported that they got difficulties in evaluating reliable sources for their academic writing as well as analyzing them. Several studies have suggested critical digital literacy for teaching and assessing students in engaging with 
technologies (Goodsett, 2020; Hutchinson \& Novotny, 2018; Kong, 2014). In general, there is similarity between the perception of pre-service teachers regarding plagiarism issue in this study and the study by Singh and Ganapathy (2018) showing that the students lacked of understanding of the plagiarism concept and distinguishing between plagiarism and non-plagiarism act. In addition, a study by Santoso and Paramartha (2019) argued that the major challenges on plagiarism were how to find reliable references and to paraphrase sentences in academic writing. Surprisingly, one unanticipated finding was that traditional mindset contributed to the students' development of digital literacy.

\section{Pre-service teachers' digital literacy competencies in EFL academic writing}

Digital literacy in terms of communication competences was found to be predominant since pre-service teachers as digital natives have been engaging the technologies in their day to day activities. This is to say, as digital natives, they naturally have the ability to use digital technologies (Prensky, 2001). Some common communication tools for communication included social networking cites, instant messaging services, video/audio conferencing services, video sharing, blogs/vlogs/personal websites, email platforms, and google forms. However, Google Scholar was still seldom used in their academic writing.

Despite the fact that participants faced the challenges concerning online safety issue such as plagiarism, they were aware of the issue of copyright, digital footprint, and plagiarism. This finding supports the study of Singh and Ganapathy (2018) that identified plagiarism was still the problem in academic writing. Further, in finding information, pre-service teachers tended to use online dictionaries and browse Google to find reputable online journals and other references. However, the use of application to retrieve and analyze academic citation was still seldom used. It indicates that they still utilized common tools to search online than to maximize the facilities offered by several free applications available in the Internet. This might happen due to less knowledge of those applications. In addition, the dimension of finding information is closely related to the critical thinking in analyzing and evaluating information from the Internet for their academic writing. Since there are many sources either reliable or not that are available in the Internet, selecting the trusted sources becomes crucial point. Moreover, developing ideas and establishing topics connectivity from different references still became the obstacles.

Participants reported that they had no problems concerning functional skills in digital literacy for academic writing such as the use of word processing application, spread sheet application, presentation application, online learning management system,
Google docs, editor platforms, and grammar checker. However, the study indicates that the use of paraphrasing-summarizing online tools, data analysis software, and reference management softwares such as NVIVO, SPSS, and Mendeley were still under explored. A possible explanation for this might be that those applications are more complicated than the others and therefore require more knowledge and practices. Consequently, this is the gap in which digital literacy training is indispensable as being suggested by OzdamarKeskin et al. (2015).

Other aspects of digital literacy for academic writing in terms of collaboration and creativity. Collaborative writing can be done using various online tools. As being explained before that, online collaboration supported the development of digital literacy (Fu \& Pow, 2011; Pow \& Fu, 2012). Focusing on creativity, pre-service teachers seemed to be less experienced in creating digital images and digital videos. Several study suggested digital composition which integrated multimodal forms in the process of writing activities (Archer, 2017; Bezemer \& Kress, 2008; Bohannon, 2015). Finally, digital culture as one of digital literacy dimensions to identify the participants' involvement in online academic communities as part of academic culture. It was reported that pre-service teachers joined social media, messaging services group, and YouTube channels. However, the involvement in organization websites, professional networking, and webinar on the topic of academic writing was still low. It seems possible that the result due to having no idea or even lack of interest in joining professional organization and networking such as Academia or ResearchGate. The studies suggested that digital technologies have become the integral part of our life as part of digital culture (Viñals Blanco et al., 2014; Wheeler, 2013).

\section{CONCLUSION}

The study has identified the pre-service teachers' conceptions of digital literacy in academic writing context and revealed four themes of basic conception of digital literacy, competences related to digital literacy, awarness of the importance of digital literacy, and challenges of digital literacy. It was also shown that the conception of digital literacy was merely associated with the ability of using technology for writing. The study also set out to determine pre-service teachers' competences concerning the predominant dimensions of digital literacy including critical thinking, online safety skills, digital culture, collaboration and creativity, finding information, communication, and functional skills. In general, the finding suggests that despite lack of understanding of critical thinking and digital culture towards digital literacy, pre-service teachers performed the competencies of finding information, 
communication, and functional skills. Taken all together, these results suggest the space of the importance of teaching digital literacy in the academic writing. In addition, this research will serve as a base of future studies in developing digital literacy framework in English language education particularly in English academic writing.

\section{LIMITATIONS}

Despite the strengths of the study, this research has some limitations. First, the findings related to the pre-service teachers' competences of digital literacy in EFL academic writing context were descriptively analyzed in general. An interesting direction for future work would be examining the level of preservice teachers' competences based on their specific demography to better understand the depth of their competences. Second, the participants in this study were taken from one institution as a case study, and they represented one major. Differences in conceptions and competences of digital literacy across multiple case studies and majors would be important to consider.

\section{REFERENCES}

Abrams, Z. I. (2019). Collaborative writing and text quality in Google Docs. Language Learning and Technology, 23(2), 22-42. https://doi.org/https://doi.org/10125/44681

Archer, A. (2017). Using multimodal pedagogies in writing centres to improve student writing. Stellenbosch Papers in Linguistics Plus, 53(1), 1-12. https://doi.org/10.5842/53-0-730

Ata, R., \& Yildirim, K. (2019). Exploring Turkish pre-service teachers' perceptions and views of digital literacy. Education Sciences, 9(40), 116. https://doi.org/10.3390/educsci9010040

Belshaw, D. (2015). The essential elements of digital literacies. Retrieved from https://dougbelshaw.com/blog/2016/01/02/digi lit-ebook-199/

Bennett, S., Maton, K., \& Kervin, L. (2008). The "digital natives" debate: A critical review of the evidence. British Journal of Educational Technology, 39(5), 775-786. https://ro.uow.edu.au/cgi/viewcontent.cgi?artic le $=2465 \&$ context $=$ edupapers

Bezemer, J., \& Kress, G. (2008). Writing in multimodal texts: A social semiotic account of designs for learning. Written Communication, 25(2), 166-195. https://doi.org/10.1177/0741088307313177

Bohannon, J. L. (2015). Not a stitch out of place: Assessing students' attitudes towards multimodal composition. Bellaterra Journal of Teaching \& Learning Language \& Literature, 8(2), 33. https://doi.org/10.5565/rev/jtl3.631

Brown, S. (2010). Likert scale examples. ANR
Program Evaluation: Iowa State University Extension.

http://www.extension.iastate.edu/ag/staff/info/l ikertscaleexamples.pdf

Calvani, A., Cartelli, A., Fini, A., \& Ranieri, M. (2008). Models and instruments for assessing digital competence at school. Journal of ELearning and Knowledge Society, 4(3), 183193. https://doi.org/10.20368/1971-8829/288

Carretero, S., Vuorikari, R., \& Punie, Y. (2017). DigComp 2.1: The Digital Competence Framework for Citizens. In Publications Office of the European Union. https://doi.org/10.2760/38842

Chun, D., Smith, B., \& Kern, R. (2016). Technology in language use, language teaching, and language learning. Modern Language Journal, 100, 64-80. https://doi.org/10.1111/modl.12302

Cote, T. J., \& Milliner, B. (2017). Preparing Japanese students' digital literacy for study abroad: Is more training needed? JALT CALL Journal, 13(3), 187-197. http://journal.jaltcall.org

Elola, I., \& Oskoz, A. (2017). Writing with 21st century social tools in the L2 classroom: New literacies, genres, and writing practices.

Journal of Second Language Writing, 36(May 2016), 52-60. https://doi.org/10.1016/j.jslw.2017.04.002

Ene, E., \& Upton, T. A. (2018). Synchronous and asynchronous teacher electronic feedback and learner uptake in ESL composition. Journal of Second Language Writing, 41(October 2017), $1-13$. https://doi.org/10.1016/j.jslw.2018.05.005

Ferrari, A. (2013). DIGCOMP: A Framework for developing and understanding digital competence in Europe. Joint Research Centre of the European Commission. https://doi.org/10.2788/52966

Fu, J., \& Pow, J. (2011). Fostering Digital Literacy through Web-based Collaborative Inquiry Learning--A Case Study. Journal of Information Technology Education, 10. https://eric.ed.gov/?id=EJ930401

García-Martín, J., \& García-Sánchez, J. N. (2017). Pre-service teachers' perceptions of the competence dimensions of digital literacy and of psychological and educational measures. Computers and Education, 107, 54-67. https://doi.org/10.1016/j.compedu.2016.12.010

Goodsett, M. (2020). Best practices for teaching and assessing critical thinking in information literacy online learning objects. Journal of Academic Librarianship, 46(5), 102163. https://doi.org/10.1016/j.acalib.2020.102163

Hague, C., \& Payton, S. (2010). Digital literacy across the curriculum: A futurelab handbook. Futurelab. Retrieved from 
www.futurelab.org.uk

Hutchinson, L., \& Novotny, M. (2018). Teaching a critical digital literacy of wearables: A feminist surveillance as care pedagogy. Computers and Composition, 50, 105-120. https://doi.org/10.1016/j.compcom.2018.07.00 6

Jewitt, C. (2005). Multimodality, "reading" and "writing" for the 21st century. Discourse: Studies in the Cultural Politics of Education, 26(3), 315-331. https://doi.org/10.1080/01596300500200011

Jisc. (2015). Developing students' digital literacy. https://www.jisc.ac.uk/guides/developingstudents-digital-literacy

Kong, S. C. (2014). Developing information literacy and critical thinking skills through domain knowledge learning in digital classrooms: An experience of practicing flipped classroom strategy. Computers and Education, 78, 160173. https://doi.org/10.1016/j.compedu.2014.05.009

Kurniasih, N., Kurniawati, N., Yulianti, Y., Rahim, R., Sujito, S., Ikhwan, A., Aimang, H. A., Haluti, F., Putri, L. D., \& Napitupulu, D. (2018). The utilization of search engines by students of the Library and Information Science Program at Universitas Padjadjaran. Journal of Physics: Conference Series, 1114(1). https://doi.org/10.1088/17426596/1114/1/012085

Lam, C., \& Wong, C. (2015). Challenges for Digital Literacy in English Curriculum. 32-36.

List, A. (2019). Defining digital literacy development: An examination of pre-service teachers' beliefs. Computers and Education, 138(April), 146-158. https://doi.org/10.1016/j.compedu.2019.03.009

List, A., Brante, E. W., \& Klee, H. L. (2020). A framework of pre-service teachers' conceptions about digital literacy: Comparing the United States and Sweden. Computers and Education, 148, 103788. https://doi.org/10.1016/j.compedu.2019.10378 8

Mackey, A., \& Gass, S. M. (2005). Second language reseacrh: Methodology and design. Lawrence Erlbaum Associates. Retrieved from https://www.manaraa.com/upload/8be2a1cf6275-4941-971c-ae6446630635.pdf

Martin, A. (2006). Literacies for the digital age. In A. Martin \& D. Madigan (Eds.), Digital literacies for learning (pp. 3-25). Facet.

Nabhan, S. (2019). Bringing multiliteracies into process writing approach in ELT classroom : Implementation and reflection. EduLite Journal of English Education, Literature and Culture, 4(2), 156-170. http://dx.doi.org/10.30659/e.4.2.156-170

Nabhan, S., \& Hidayat, R. (2018). Investigating literacy practices in a university EFL context from multiliteracies and multimodal perspective: A case study. Advances in Language and Literary Studies, 9(6), 192-199. https://doi.org/http://dx.doi.org/10.7575/aiac.al 1s.v.9n.6p. 192

NLG. (1996). A pedagogy of multiliteracies: Designing social futures. Harvard Educational Review, 66(1), 60-92.

Ozdamar-Keskin, N., Ozata, F. Z., Banar, K., \& Royle, K. (2015). Examining digital literacy competences and learning habits of open and distance learners. Contemporary Educational Technology, 6(1), 74-90.

https://www.cedtech.net/download/examiningdigital-literacy-competences-and-learninghabits-of-open-and-distance-learners-6140.pdf

Phuapan, P., Viriyavejakul, C., \& Pimdee, P. (2016). An analysis of digital literacy skills among Thai university seniors. International Journal of Emerging Technologies in Learning, 11(3), 24-31. https://doi.org/10.3991/ijet.v11i03.5301

Pow, J., \& Fu, J. (2012). Developing digital literacy through collaborative inquiry learning in the web 2.0 environment - an exploration of implementing strategy. Journal of Information Technology Education: Research, 11(1), 287299. https://doi.org/10.28945/1737

Prensky, M. (2001). Digital natives, digital imigrants. On the Horizon, 9(5), 1-6. https://www.marcprensky.com/writing/Prensky - Digital Natives, Digital Immigrants Part1.pdf

Rambousek, V., Štípek, J., \& Vaňková, P. (2016). Contents of digital literacy from the perspective of teachers and pupils. ProcediaSocial and Behavioral Sciences, 354-362. https://doi.org/10.1016/j.sbspro.2016.02.101

Saeed, M. A., \& Ghazali, K. (2017). Asynchronous group review of EFL writing: Interactions and text revisions. Language Learning and Technology, 21(2), 200-226.

Santoso, M. H., \& Paramartha, A. A. G. Y. (2019). Indonesian English university students' perceptions on plagiarism in the online world era. Journal of ELT Research, 4(2), 165-177.

Shariman, T. P. N. T., Razak, N. A., \& Noor, N. F. M. (2012). Digital literacy competence for academic needs: An analysis of Malaysian students in three universities. Procedia - Social and Behavioral Sciences, 69(ICEEPSY 2012), 1489-1496. https://doi.org/10.1016/j.sbspro.2012.12.090

Singh, M. K. M., \& Ganapathy, M. (2018). Understanding plagiarism from the lens of first year tertiary level students. Pertanika Journal of Social Sciences and Humanities, 26(T), 159-177. http://www.pertanika.upm.edu.my/pjssh/brows 
e/archives?article=JSSH-2576-2017

Son, J.-B. (2015). Digital Literacy. Retrieved from http://drjbson.com/projects/dl/

Son, J.-B., Park, S. S., \& Park, M. (2017). Digital literacy of language learners in two different contexts. JALT CALL Journal, 13(2), 77-96. https://doi.org/10.29140/jaltcall.v13n2.213

Viñals Blanco, A., Bayón Martín, F., \& Ortega Nuere, C. (2014). Promoting digital competences for the enjoyment of culture: new literacy challenges. ENCATC Journal of Cultural Management and Policy, 4(1), 68-77. http://encatc.org/pages/fileadmin/user_upload/ Journal/ENCATC_Journal_VOL_4_Issue_1.p df\#page $=68$

Wheeler, S. (2013). Digital literacies for engagement in emerging online cultures. $E L C$ Research Paper Series, 5, 14-25.

Zheng, B., \& Warschauer, M. (2017). Epilogue: Second language writing in the age of computer-mediated communication. Journal of Second Language Writing, 36(xxxx), 61-67. https://doi.org/10.1016/j.jslw.2017.05.014 